\title{
Germination Response of Jojoba Seeds under Different Temperature Conditions of the Cholistan Desert of Bahawalpur
}

\author{
Malik Muhammad Yousaf ${ }^{*}$, Muhammad Mohsin Raza ${ }^{1 *}$, Mumtaz Hussain ${ }^{1}$, Jahangir Shah ${ }^{1}$, Rao Wali \\ Muhammad $^{1}$, Sami Ullah ${ }^{2,3}$, Hera Gul ${ }^{4}$, Ijaz Ahmad ${ }^{5}$ and Muhammad Zeshan ${ }^{6}$
}

${ }^{1}$ Pakistan Agriculture Research Center, Arid Zone Research Institute, Bahawalpur, Pakistan; ${ }^{2}$ Institute of Agricultural Resources and Regional Planning, Chinese Academy Agricultural Sciences Beijing, China; ${ }^{3}$ Department of Biology University of Okara Pakistan; ${ }^{4}$ Department of Horticultural Science, Faculty of Agriculture and Environmental sciences, The Islamia University of Bahawalpur, Pakistan; ${ }^{5}$ Excotology Research Program, National Agriculture Research Center (NARC) Islamabad, Pakistan; ${ }^{6}$ National Institute for Genomic and Advance Biotechnology NARC Islamabad, Pakistan.

\begin{abstract}
Among arid zone plant species, Jojoba (Simmondsia chinensis), being an evergreen, perennial, multi-stemmed, and multipurpose plant has attracted wide attention due to its economic value, potential byproducts and ability to withstand vagaries of the desert environment. By realizing the economic importance of this high-value desert plant, a pioneer study on seed germination response to various agro-climatic factors was conducted at the Arid Zone Research Institute Bahawalpur. Healthy jojoba seeds were sown at the fortnightly intervals by dividing the whole year into 16 treatments to identify the optimum sowing time for the Cholistan desert of Bahawalpur. The results revealed that maximum germination rate of $85.63 \%, 85.93 \%$, and $82.83 \%$ were found in treatment $16^{\text {th }}$ September during the whole study period (2011-14). The $16^{\text {th }}$ of March, $16^{\text {th }}$ September, and $1^{\text {st }}$ August were the other suitable sowing times for jojoba as these showed $82.37 \%, 75.47 \%$, and $71.57 \%$ of germination respectively.

Received | July 17, 2020; Accepted | January 04, 2021; Published | March 23, 2021

*Correspondence | Malik Muhammad Yousaf, Pakistan Agriculture Research Center, Arid Zone Research Institute, Bahawalpur, Pakistan; Email: malikparc@gmail.com, mohsinraza@parc.gov.pk

Citation | Yousaf, M.M., M.M. Raza, M. Hussain, J. Shah, R.W. Muhammad, S. Ullah, H. Gul, I. Ahmad and M. Zeshan. 2021. Germination response of jojoba seeds under different temperature conditions of the Cholistan Desert of Bahawalpur. Pakistan Journal of Agricultural Research, 34(2): 273-277.

DOI | http://dx.doi.org/10.17582/journal.pjar/2021/34.2.273.277

Keywords | Jojoba, Simmondsia chinensis, Germination, Agro-climatic factors, Bahawalpur, Pakistan
\end{abstract}

\section{Introduction}

$\int$ ojoba is an economical desert plant, which can be grown successfully in arid and semi-arid deserts. It is a dioeciously, perennial, evergreen, woody shrub scientifically known as Simmondsia chinensis. Jojoba is considering very precious plant that can survive under drought, saline water, extreme hot climatic conditions and resists pest attack. An interesting fact about the jojoba plant is that nature has covered its leaves with a waxy coating/sheet, which helps to reduce the evapotranspiration from its leaves thus reducing the loss of moisture at a very minimum level. This probably is one of the most important reasons for its survival under desert conditions. Jojoba seed used in cosmetic industries because it contains 40 to $50 \%$ oil which 'is useful for lotions, massage oils, lipsticks, smoothing creams and nail polishes. It, $s$ also has potential for lubricant, printing and pharmaceutical industries (Benzioni et al., 1999). The oil extracted from Jojoba is usually called as "Liquid Gold". The chemical composition of jojoba oil resembles that of whale fish oil. As a strict ban is being observed on the hunting of whale fish at the international level, June 2021 | Volume 34 | Issue 2 | Page 273 
increased attention is being paid since the 1970's to the alternate source of oil (i.e. jojoba oil) on a commercial scale. There is, however, a vital need to introduce this plant at a larger scale and make good use of its fruit/seed and the other by-products, which has largely been ignored in the past (Nechiporenko, 1989).

Some scientist also reported that Jojoba seed germination affected by various abiotic stresses (temperature, moisture, $\mathrm{pH}$, soil type, different salinity levels and drought conditions). Thomson in 1982 examined seed germination rate with alkaline sandy media and temperature ranged at 80 to $100^{\circ}$ $\mathrm{F}$ - and 100 to $110^{\circ} \mathrm{F}$. Jojoba germination rate (75 to $78 \%)$ recorded under the temperature of 21 to $35^{\circ} \mathrm{C}$ (Kuepper, 1981). The Scientist also concluded that either October or February was suitable for sowing the seed and have high germination rate (Harsh et al., 1987).

As this plant is exotic thus, most of the farmers of the country are not familiar with its cultivation and production technology. There is a necessity of conducting various researches on different aspects to develop a sound technology package as a source of knowledge for farmers, investigator, and all stakeholders who are interested in this crop. By realizing the importance of this plant in desert areas a pioneer study was initiated with intention of observing the germination response of Jojoba seeds under various agro-climatic conditions in the Cholistan desert of Bahawalpur, Pakistan.

\section{Materials and Methods}

The study pertaining to the germination response of jojoba seed (Simmondsia chinensis) under various agro-climatic factors was conducted at the Arid Zone Research institute (AZRI), Bahawalpur. There were sixteen treatments in this study i.e. $1^{\text {st }} \mathrm{July}\left(\mathrm{T}_{1}\right), 16^{\text {th }}$ July (T2), $1^{\text {st }}$ August (T3), $16^{\text {th }}$ August (T4), $1^{\text {st }}$ September (T5), $16^{\text {th }}$ September (T6), $1^{\text {st }}$ October (T7), $16^{\text {th }}$ October (T8), $1^{\text {st }}$ November (T9), $16^{\text {th }}$ November (T10), $1^{\text {st }}$ February (T11), $16^{\text {th }}$ February (T12), $1^{\text {st }}$ March (T13), 16 ${ }^{\text {th }}$ March (T14), $1^{\text {st }}$ April (T15) and $16^{\text {th }}$ April (T16). All treatments were randomized in three replications. Ten bags were kept for every treatment in each replication. The trial was conducted according to completely randomized design. The sowing of jojoba seeds were done in polythene bags with depth $28 \mathrm{~cm}$ and $12 \mathrm{~cm}$ width. The polythene bags were punctured from different positions with the help of a needle to facilitate the aeration and seepage of excessive water. The soil media with the ratio of 1:1 was made of sand and silt and the polythene bags were filled with the soil media. Healthy, bold seeds of jojoba were sown in $1 \mathrm{~cm}$ deep in a horizontal position and covered with the same soil media. After sowing, water was applied with hand sprinkler irrigation was made daily in summer and on alternate days during winter. The data of germination percentage were recorded, compiled, and subjected to statistical analysis. The data of agro-climatic conditions were obtained from the metrological station, in Bahawalpur.

\section{Results and Discussion}

The use of jojoba seeds is smooth and black in colour. Jojoba seeds have $8-17 \mathrm{~mm}$ in length, $5-11 \mathrm{~mm}$ in cross section and seed weight $61-157 \mathrm{gm} / 100$ seeds. Positive correlation recorded between seed size and oil content. Oil quality was exhibited variation regardless of geographic origin of seed (Yermanos, 1979; Ullah et al., 2020a). Pakistan have harsh temperature changes issues and jojoba have ability to perform better against wide temperature range from $18-40^{\circ} \mathrm{C}$ (NIPS, 201213, Al-Obaidi et al., 2017). In our study, there were 16 treatments with different temperatures and we measured the germination percentage. In previous, research scientists reported germination percentage of jojoba and other oil seeded crops readily growing fast in sandy, clay soil, and against different temperature ranges (Gentry, 1958; Domènech and Vilà, 2008; Ullah et al., 2019). The results given in Table 1 show that during 2012-2013, maximum germination rate of $85.63,76.27$, and $75.47 \%$ followed by relative maximum temperature $37.1,38.1$, and $38.9^{\circ} \mathrm{C}$. On the other relative minimum and maximum temperature affected the germination percentage. Relative high temperature, $38.1^{\circ} \mathrm{C}$, and $40.1^{\circ} \mathrm{C}$ affected germination percentage and recorded 15.57 and $17.37 \%$. Relative lower temperature $22.4^{\circ} \mathrm{C}$ affected germination percentage and recorded 20.33 during February 2012-2013. Scientists working on the jojoba crop also reported the same results about temperature effects on germination percentage (Miwa, 1984). The relative humidity percentage data of these months are higher than other months and the maximum relative humidity $70 \%$. While on the other rainfall average $(\mathrm{mm})$ in September and October are 0.6 and $11.6 \mathrm{~mm}$ respectively and during July annual 


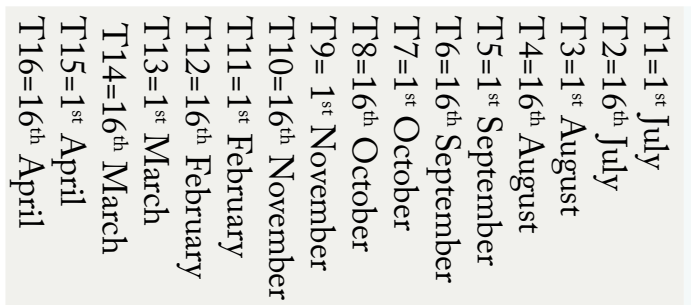

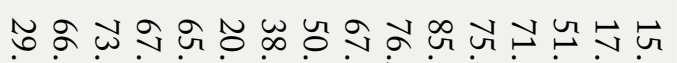

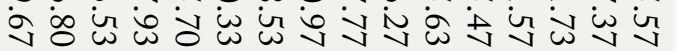
व

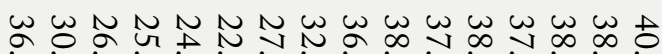

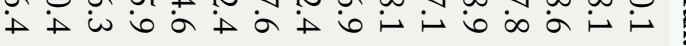

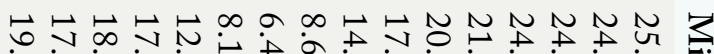

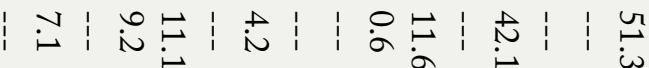

씹ำ $\dot{v}$ 거 $Q \forall>\forall \Theta \Omega$ TH

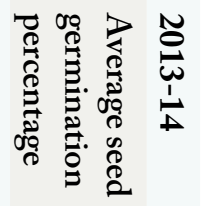

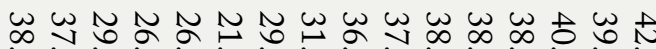

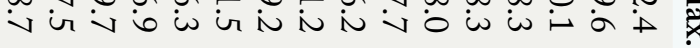

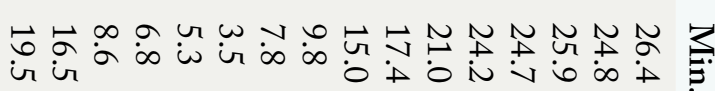

๓

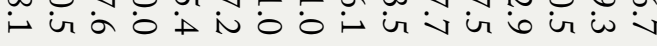

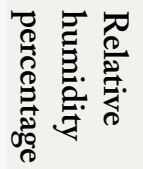

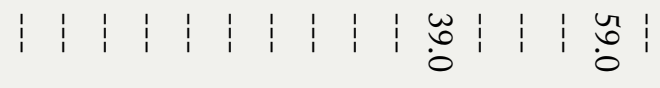

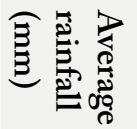

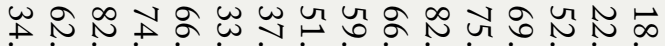
$\dot{\delta}$ भा

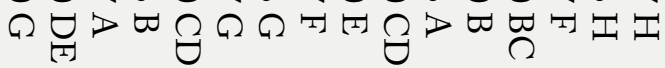

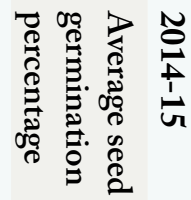

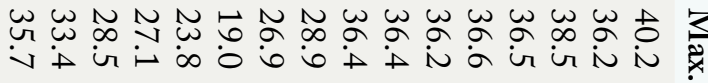

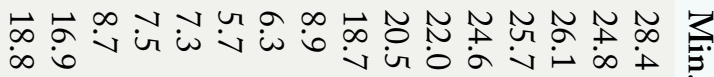

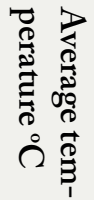

जิ

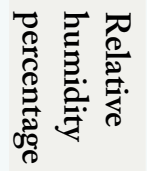

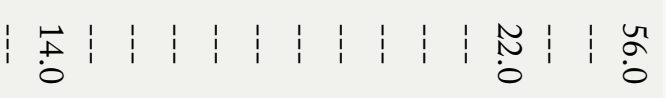

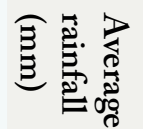


rainfall was recorded higher (51.3) than other months. Which showed that, relative humidity percentage and annual rainfall affects jojoba germination percentage (Shadrack, 2016; Yermanos and Duncan, 1976; Ullah et al., 2020b). During 2013-14, the germination percentage of jojoba was higher (85.93 and 72.03\%) during September and October. Relative humidity percentages have similar effects like 2012-2013, while the annual rain was $39 \%$, which is higher than the previous year. During 2014-15, the germination percentage was higher (82.83 and 75.60) during September $1^{\text {st }}$ and September $16^{\text {th }}$. The maximum temperatures averages of these months were 36.2 and $36.2^{\circ} \mathrm{C}$. While during the most important part of this year, the relative humidity percentage was higher than in previous years, especially the humidity percentage was higher (81.5 and 86.1) than other months. Annual rainfall during $1^{\text {st }}$ July $2014-15$ was $56 \mathrm{~mm}$, which increased the germination percentage of this year as compared with others. Data regarding to this month showed that relative humidity percentage also affect the germination percentage of jojoba (Edlabadkar et al., 2004; Bala et al., 2017).

Based on of three years data, recorded we conclude that, higher temperature effects jojoba germination percentage. Higher average percentage of temperature increased germination rate while lower temperatures decreased the germination. In Pakistan, during the month of September and October temperatures are suitable for germination of jojoba seed. We also concluded that, temperatures with higher annual rainfall and a relative humidity is favourable for germination of jojoba.

\section{Novelty Statement}

To the best of our knowledge this is the first study conducted on germination response of jojoba under arid conditions of Cholistan Desert.

\section{Author's Contribution}

Malik Muhammad Yousaf: Conceived the idea and provided technical input at every stage.

Muhammad Mohsin Raza, Jahangir Shah and Rao

Wali Muhammad: Wrote the manuscript.

Mumtaz Hussain: Presented methodology.

Sami Ullah: Did SPSS analysis.

Hera Gul: Provided technical input at every stage.

Ijaz Ahmad: Overall management of the article.
Muhammad Zeshan: Managed references.

\section{Conflict of interest}

The authors have declared no conflict of interest.

\section{References}

Al-Obaidi, J.R., M.H. Farouq, N.S. AlKhalifah A. Al-Soqeer and M.F. Attia. 2017. A review on plant importance, biotechnological aspects, and cultivation challenges of jojoba plant. Biol. Res., 50: 25. https://doi.org/10.1186/s40659017-0131-X

Bala, R., J.S. Laura and V.S. Benwal. 2017. Assessment of viability and enhancement of germination potential of jojoba seeds under in vitro condition using plant growth regulator. Plant Cell Biotechnol. Mol. Biol., 18(7 and 8): 552-558.

Benzioni, A., E. Shiloh, and M. Ventura. 1999. Yield parameters in young jojoba plants and their relation to actual yield in later years. Ind. Crops Prod. 10:85-89.

Domenech, R. and M. Villa. 2008. Cortaderia selloana seed germination under different ecological condition. Acta Oecologica, 33(1): 93-96. https://doi.org/10.1016/j. actao.2007.09.004

Edlabadkar, M.V., A. Deogirikar, P.B. Kale and K.P. Arulka. 2004. Evaluation of jojoba seed germination inside and outside poliyhouse. 15(1): 57-59.

Gentry, H.S., 1958. The natural history of Jojoba (Simmondsia chinensis) and its cultural aspects. Econ. Bot., 12: 261-295. https://doi. org/10.1007/BF02859772

Harsh, L.N., J.C. Tewari, D.S. Patwal and G.L. Meena.1987. Package of practices for cultivation of jojoba (Simmondsia chinensis) in Arid Zone. Central Arid Zone Research Institute, Jodhpur, India.

Kuepper, T.A., 1981. Jojoba oil investment of the eighties. Desert Pacific Jojoba, Oxnard, CA. Mann, H.S. and K.D. Muthana. 1982. Jojobaits prospects in Indian arid zone. Myforest, pp. 71-78.

Miwa, T.K., 1984. Structural determination and uses of Jojoba Oil.J. Am. Oil Chem. Soc., 61(2): 407-410.https://doi.org/10.1007/BF02678804 National Institute of Population Studies (NIPS) 
and ICF International. 2013. Pakistan demographic and health survey, 2012-13. Islamabad, Pakistan and Maryland, USA: NIPS and ICF International.

Nechiporenko, V.N., 1989. Industrial cultivation of new oil-producing plant Simmondsiachinensis Link in arid Zone. Problemy Osvoeniya Pustyn, (4): 73-75.

Shadrack, 2016. Characterization, propagation and management of jojoba (Simmondsiachinensis L.) In semi-arid areas of Voi, Kenya.

Thomson, P.H., 1982. Jojoba Handbook. $3^{\text {rd }}$ Edn., Bonsall Publications, 4339 Holly Lane Bonsall, California, USA.

Ullah, S., C. Ai, W. Ding, R. Jiang, S. Zhao, J. Zhang, W. Zhou, Y. Hou and P. He. 2019. The response of soil fungal diversity and community composition to long-term fertilization. Appl. Soil Ecol., 140: 35-41. https://doi. org/10.1016/j.apsoil.2019.03.025

Ullah, S., C. Ai, S. Huang, D. Song, T. Abbas, J.
Zhang, W. Zhou and P.He. 2020a. Substituting ecological intensification of agriculture for conventional agricultural practices increased yield and decreased nitrogen losses in North China. Appl. Soil Ecol., 147: 103395. https:// doi.org/10.1016/j.apsoil.2019.103395

Ullah, S., P. He, C. Ai, S. Zhao, W. Ding, D. Song, J. Zhang, S. Huang, T. Abbas and W.Zhou. 2020b. How do soil bacterial diversity and community composition respond under recommended and conventional nitrogen fertilization regimes? Microorganisms, 8: 1193. https://doi. org/10.3390/microorganisms8081193

Yermanos, D.M. and C.C. Duncan. 1976. Quantitative and qualitative characteristics of jojoba seed. J. Am. Oil Chem. Soc., 53(2): 8082. https://doi.org/10.1007/BF02637398

Yermanos, D.M., 1979. Jojoba a crop whose time has come. California Agric., (Jul - Aug.), pp. $4-11$. 